\title{
Pengaruh Penggunaan Rebusan Seledri terhadap Penurunan Tekanan Darah pada Penderita Hipertensi di Wilayah Kerja Puskesmas Cenggu Tahun 2018
}

\author{
Nurwahidah $^{1(\mathrm{CA})}$, Jubair $^{2}$ \\ ${ }^{1(\mathrm{CA})}$ Jurusan Keperawatan, Poltekkes Kemenkes Mataram, Indonesia; email: wahidahn18@gmail.com \\ ${ }^{2}$ Jurusan Keperawatan, Poltekkes Kemenkes Mataram, Indonesia
}

\begin{abstract}
Hypertension is called the silent killer because it is asymptomatic. The problem of this study is the high number of patients with hypertension, therefore it is necessary to take action in addition to pharmacology as well as non-pharmacological, one of which is the provision of celery boiled water in order to reduce the increase in blood pressure. The purpose of this study was to determine the effect of celery cooking water on the reduction of systolic and diastolic blood pressure in patients with hypertension in the working area of the Cenggu Community Health Center. The method used is the True Experiment approach with pre-test and post-test designs. The research sample consisted of 16 people consisting of two groups namely the treatment group and the control group, with purposive sampling technique. The results of this study showed that there were differences in systolic and diastolic blood pressure values before, on the first day and the second day after giving Celery Stew with a significance value of $\mathrm{p}<0.05$. There is a significant influence on the delivery of celery stew water on the reduction of blood pressure in hypertension sufferers.
\end{abstract}

Keywords: Celery; Blood Pressure; Hypertension

\begin{abstract}
ABSTRAK
Hipertensi disebut silent killer karena sifatnya asimtomatik. Masalah penelitian ini masih tingginya angka penderita hipertensi, oleh karena itu diperlukan tindakan selain farmakologi juga non farmakologis salah satunya adalah pemberian Air rebusan seledri agar dapat menekan peningkatan tekanan darah. Tujuan penelitian ini untuk mengetahui pengaruh Air rebusan seledri terhadap penurunan tekanan darah sistolik dan diastolik pada penderita Hipertensi di Wilayah Kerja Puskesmas cenggu. Metode yang digunakan pendekatan True Experiment dengan rancangan pre test dan post test. Sampel penelitian berjumlah 16 orang terdiri dari dua kelompok yakni kelompok perlakuan dan kelompok kontrol, dengan tekhnik Purposive sampling. Hasil penelitian ini menunjukkan ada perbedaan nilai tekanan darah sistolik dan diastolik sebelum, pada hari pertama dan hari kedua setelah pemberian Air Rebusan Seledri dengan nilai signifikansi $\mathrm{p}<0,05$. Ada pengaruh yang signifikan Pemberian Air Rebusan Seledri terhadap penurunan Tekanan darah Penderita Hipertensi.
\end{abstract}

Kata Kunci : Seledri; Tekanan Darah; Hipertensi

\section{PENDAHULUAN}

Hipertensi adalah suatu keadaan dimana seseorang mengalami peningkatan tekanan darah di atas normal yang mengakibatkan peningkatan angka kesakitan (morbiditas) dan angka kematian/ mortalitas. Tekanan darah 140/90 mmHg didasarkan pada dua fase dalam setiap denyut dipompa oleh jantung dan fase diastolik 140 menunjukan fase darah yang sedang di pompa oleh jantung dan fase diastolik 90 menunjukan fase darah yang kembali (Menurut Endang Triyanto). Menurut WHO batas normal tekanan darah adalah 120-140 mmHg tekanan sistolik dan 80- $90 \mathrm{mmHg}$ tekanan diastolik. Seseorang dinyatakan mengidap hipertensi bila tekanan darahnya>140/90 mmHg. Tekanan darah yang tinggi merupakan salah 
satu factor resiko untuk stroke, serangan jantung, gagal jantung, aneurisma arterial, dan merupakan penyebab utama gagal jantung kronis (Tekanan Darah Tinggi) hipertensi adalah suatu keadaan dimana seseorang mengalami peningkatan tekanan darah di atas normal yaitu> 140/90mmHg.

Menurut Sidabutar (dikutip soeparman, 1990;205), hipertensi didefinisikan sebagai suatu tingkat tekanan darah dimana komplikasi yang timbul menjadi nyata. Prelevansi penderita hipertensi di Indonesia cukup tinggi yaitu $7 \%$ sampai $22 \%$. Berdasarkan hasil survey penderita yang berujung pada penyakit jantung $75 \%$, stroke $15 \%$ dan gagal ginjal 10\%. Penelitian juga menunjukan prevalensi hipertensi juga meningkat dengan bertambahnya usia. Dari berbagai penelitian epidemiologis yg dilakukan di Indonesia menunjukan 1,8\%-28,6\% penduduk yg berusia di atas 20 tahun adalah penderita hipertensi. Menurut penelitian Boedi Darmoyo (2005) di dapatkan bahwa antara 1,8\%-28,6\% penduduk dewasa adalah menderita hipertensi dengan rata-rata usia antara 35-65 tahun tahun. Hal disebabkan oleh beberapa factor yaitu kurangnya aktivitas fisik, berat badan lebih, gangguan dari perubahan hormonal serta factor genetika, serta kurangnya pengetahuan penderita hipertensi dan keluarga tentang pencegahan, penanganan dan perawatan dengan baik dan benar (Yudini, 2006).

Dari data PKM Cenggu Kec. Belo di desa Renda yang menderita hipertensi pada tahun 2016 sebanyak 14 penderita hipertensi dengan perbandingan laki-laki sebanyak 6 dan wanita sebanyak 8 penderita, sedangkan data pada tahun 2017 sebanyak 16 penderita hipertensi dengann perbandingan laki-laki sebanyak 7 dan wanita 9 penderita hipertensi.Pengaruh hipertensi pada organ tubuh atau organ target dianggap sebagai peninggian tekanan darah. Hipertensi dapat menyebabkan kerusakan pada sel sel epitel tunika intima arteri yang berakibat atau merangsang atherosclerosis dan thrombus. Sedangkan organ target yang terkena adalah jantung, otak, ginjal, dan mata.

Mencegah hipertensi tidak menyebabkan komplikasi lebih lanjut diperlukan penanganan yang tepat dan efisien. Menurut Marlia (2009) penanganan hipertensi secara umum yaitu secara farmakologis dan non-farmakologis. Penanganan farmakologis terdiri atas pemberian obat bersifat diuretik, simpatetik, betabloker, dan vasodilator dengan memperhatikan tempat, mekanisme kerja dan tingkat kepatuhan. Sedangkan Penanganan non-farmakologis yaitu penurunan berat badan, olah raga secara teratur, diet rendah lemak dan garam, dan terapi komplementer. Penanganan non-farmakologis tidak memiliki efek samping berbahaya seperti penanganan farmakologis. Sehingga masyarakat lebih menyukai penanganan non- farmakologis dari pada secara farmakologis (Marlia 2009). Salah satu penanganan non farmakologis dalam menyembuhkan penyakit hipertensi terapi komplementer. Terapi komplementer bersifat terapi pengobatan alamiah diantaranya adalah dengan terapi herbal, terapi nutrisi, meditasi, akupuntur, aromaterapi (Sustranidkk, 2005).

Jenis obat yang digunakan dalam terapi herbal yaitu seledri atau celery ( Apium graveolens), bawang putih atau garlic (Allium Sativum), bawang merah atau onion (Alliumcepa), tomat (Lyocopercison lycopersicum), semangka (Citrullus vulgaris). (Sustrani, dkk 2005). Seledri atau celery (Apium graveolens) merupakan salah satu jenis terapi herbal untuk menangani penyakit hipertensi mengandung apigenin yang sangat bermanfaat untuk mencegah penyempitan pembuluh darah dan tekanan darah tinggi. Selain itu, mengandung pthalides dan magnesium yang baik untuk membantu 
melemaskan otot-otot sekitar pembuluh darah arteri dan bantu menormalkan penyempitan pembuluh darah arteri. Pthalides dapat mereduksi hormone stres yang dapat meningkatkan darah (Afifah, 2009).

Selain mengandung apigenin dan pthalides seledri juga mengandung gizi yang tinggi, vitamin A, B1, B2, B6 dan juga vitamin C. Seledri juga kaya pasokan kalium, asam folic, kalsium, magnesium, zat besi, fosfor, sodium dan banyak mengandung asam amino esensial. Pada pasokan kalium sangat bermanfaat untuk terapi darah tinggi (Afifah, 2009). Apigenin yang terkandung dalam ekstrak seledri memperlambat detak jantung dan menurunkan kontraksi jantung sehingga tekanan darah menjadi berkurang. Manito dan apiin yang terkandung dalam rebusan seledri bersifat sebagai diuretik membantu ginjal mengeluarkan kelebihan cairan dan garam dari dalam darah akan menurunkan tekanan darah. Secara tradisional digunakan untuk membantu meringankan gejala tekanan darah tinggi ringan.

\section{METODE}

Desain penelitian menggunakan metode Kuasi Eksperimen dengan one grup pre-test dan post-test. Dalam penelitian ini populasinya adalah semua penderita hipertensi berdasarkan data dari PKM Cenggu untuk desa renda pada bulan Januari sampai Oktober 2017 sebanyak 16 orang. Tehnik pengambilan sampel yang digunakan adalah "Purposive Sampling". Tekhnik pengumpulan data, menggunakan pedoman wawancara dan quesionar. Dalam penelitian ini, lembar quesioner yang digunakan adalah dengan menggunakan pertanyaan mengenai tanda dan gejala hipertensi atau tekanan darah tinggi setelah menggunakan rebusan seledri. Pada wawancara penggunaan rebusan seledri ini apabila responden menggunakan sesuai dengan panduan maka akan diberikan nilai + , tetapi apabila tidak sesuai maka diberikan nilai -. Setelah data terkumpul, maka nilai (+) dan (-) pada masing-masing jawaban wawancara akan dijumlahkan. Apabila nilai $(+)=6$ berarti responden menggunakan sesuai dengan panduan, tetapi apabila $<6$ berarti penggunaannya tidak sesuai dengan panduan. Pengolahan data pengetahuan dikatakan baik apabila nilai $76-100 \%$, cukup apabila nilai $56-75 \%$, dan kurang apabila nilai $<56 \%$, sedangkan untuk sikap positif diberi kode 1 dan sikap negatif diberi kode 0 . Melakukan pemberian skor dari jawaban responden berdasarkan tingkat pengetahuan. Bila benar di beri skor 1, bila salah di beri skor 0 . Untuk menghindari masalah etika penelitian, sebelum melakukan pengumpulan data, peneliti memberikan penjelasan tentang tujuan dan sifat keikutsertaan dalam kegiatan penelitian bersifat sukarela. Untuk menjaga agar identitas sampel penelitian tidak diketahui oleh umum, maka peneliti memberikan kode sampel penelitian untuk setiap kuesioner yang dibagikan dan data penelitian dipublikasikan atau dipresentasikan dalam bentuk data berkelompok bukan data individu.

\section{HASIL}

Penelitian ini menggunakan metode Kuasi Eksperimen dengan one grup pre-test dan post-test. Tempat penelitian dilakukan di kerja puskesmas cenggu. Total sample dalam penelitian ini adalah 16 responden. 
1. Karakteristik penderita hipertensi berdasarkan tekanan darah sebelum diberikan air rebusan seledri.

Tabel 1 distribusi penderita hipertensi sebelum di berikan air rebusan seledri

\begin{tabular}{ccccc}
\hline No & & TD sebelum & Frekuensi & Persen \\
\hline $\mathbf{1}$ & Hipertensi & 16 & 100 \\
\hline Jumlah & & & 16 & 100 \\
\hline
\end{tabular}

2. Karakteristik penderita hipertensi berdasarkan tekanan darah sesudah diberikan air rebusan seledri.

Tabel 2 distribusi penderita hipertensi sesudah di berikan air rebusan seledri

\begin{tabular}{ccccc}
\hline No & & TD sesudah & Frekuensi & Persen \\
\hline $\mathbf{1}$ & Normal & 14 & 87,5 \\
$\mathbf{2}$ & Hipertensi & 2 & 12,5 \\
\hline Jumlah & & 16 & 100 \\
\hline
\end{tabular}

3. Analisis perbedaan tekanan darah pada penderita hipertensi sebelum dan sesudah diberikan rebusan seledri.

Tabel 3 Perbedaan tekanan darah pada penderita hipertensi sebelum dan sesudah diberikan air rebusan seledri.

\begin{tabular}{|c|c|c|c|c|c|c|c|c|}
\hline \multirow{3}{*}{ Air rebusan seledri } & \multicolumn{4}{|c|}{$\begin{array}{l}\text { TD sebelum di berikan air rebusan } \\
\text { seledri } \\
\end{array}$} & \multicolumn{4}{|c|}{$\begin{array}{l}\text { TD sesudah di berikan air rebusan } \\
\text { seledri }\end{array}$} \\
\hline & \multicolumn{2}{|c|}{ Hipertensi } & \multicolumn{2}{|c|}{ Normal } & \multicolumn{2}{|c|}{ Hipertensi } & \multicolumn{2}{|c|}{ Normal } \\
\hline & $\mathrm{f}$ & $\%$ & f & $\%$ & $\mathrm{f}$ & $\%$ & $\mathrm{f}$ & $\%$ \\
\hline & 16 & 100 & 0 & 0 & 2 & 12,5 & 14 & 87,5 \\
\hline Jumlah & \multicolumn{4}{|c|}{$f=16+0=16$} & \multicolumn{4}{|c|}{$f=2+14+16$} \\
\hline & \multicolumn{8}{|c|}{$t$-test $p=0.000$} \\
\hline
\end{tabular}

Berdasarkan tabel 3 menunjukan, frekuensi tekanan darah mengalami perubahan yang signifikan, yaitu tekanan darah sebelum di berikan air rebusan seledri yang mengalami hipertensi 16 responden (100\%), mengalami penurunan TD setelah di berikan air rebusan seledri dalam batas normal sebanyak 14 $(87,5 \%)$ responden.hasil uji statistik tehnik paired T-test di dapatkan hasil $p=0,000$ atau lebih kecil dari $\alpha$ 0,005 dengan $\mathrm{T}$ temuan $=10.247$ atau lebih besar dari $\mathrm{T}$ tabel $=1.75305$ yang berarti $\mathrm{H}_{0}$ di tolah dan $\mathrm{H}_{1}$ diterima yang artinya ada pengaruh penggunaan air rebusan seledri terhadap penurunan tekanan darah pada penderita hipertensi.

\section{PEMBAHASAN}

Berdasarkan data karakteristik responden berdasarkan umur yang di tampilkan pada tabel 4.2 diketahui persentase usia responden adalah 68,8 dengan usia responden terbanyak yaitu usia 51-59 tahun tahun dan berdasarkan jenis kelamin diketahui persentase 62,5 dengan jumlah responden terbanyak 
adalah berjenis kelamin perempuan. Semakin usia seseorang bertambah maka akan terjadi perubahanperubahan pada tubuh manusia. Perubahan tubuh terjadi sejak awal kehidupan hingga lanjut usia pada semua organ dan jaringan tubuh. Hipertensi merupakan salah satu penyakit degeneratif. Umumnya tekanan darah bertambah secara perlahan dengan bertambahnya umur. Risiko untuk menderita hipertensi pada populasi $\geq 55$ tahun yang tadinya tekanan darahnya normal adalah $90 \%$ (Harmilah \& Ekwantini, 2014:28).

Bila ditinjau dari segi perbandingan antara perempuan dan laki-laki, secara umum kaum perempuan lebih banyak menderita hipertensi dibandingkan dengan laki-laki. Laki-laki mempunyai resiko lebih tinggi untuk menderita hipertensi lebih awal sedangkan pada perempuan biasanya lebih rentan terhadap hipertensi ketika sudah berumur diatas umur 50 tahun (Susilo dan Wulandari, 2011:54). Perempuan seringkali mengadopsi prilaku tidak sehat seperti merokok dan pola makan yang tidak seimbang sehingga menyebabkan kelebihan berat badan, depresi dan rendahnya status pekerjaan. Sedangkan pada kaum laki-laki, hipertensi lebih berkaitan erat dengan pekerjaan dan seperti perasaan kurang nyaman terhadap pekerjaan dan pengangguran. Tekanan darah dalam kehidupan seseorang bervariasi. Secara alami, bayi dan anak-anak memiliki secara normal memiliki tekanan darah yang jauh lebih rendah dari pada dewasa. Tekanan darah juga di pengaruhi oleh aktiftas fisik, dimana akan lebih tinggi bila beraktifitas dan lebih rendah ketika beristirahat. Tekanan darah dalam satu hari juga berbeda, paling tinggi di waktu pagi hari dan paling rendah pada saat tidur di malam hari.

Berdasarkan analisis univariat pada tabel 2 diketahui bahwa tampak kecenderungan penurunan tekanan darah. Berdasarkan tabel 1 diketahui bahwa sebelum diberi rebusan seledri tekanan darah responden masuk ke dalam kategori hipertensi dan setelah diberi rebusan seledri tekanan darah responden menurun. Hipertensi berarti tekanan darah di dalam pembuluh-pembuluh darah yang mengangkut darah dari jantung yang memompa darah keseluruh jaringan dan organ-organ sangat tinggi. Tekanan darah normal adalah 120/80 mmHg. Tekanan darah antara 120/80 mmHg dan 139/89 mmHg disebut prahipertensi dan tekanan darah lebih dari 140/90 mmHg disebut hipertensi (Susilo dan Wulandari, 2011:22). Bahaya hipertensi sangat beragam.

Apabila seseorang mengalami hipertensi maka dia juga akan mengalami komplikasi dengan penyakit lain. Hipertensi merusak organ tubuh seperti jantung (70\% penderita hipertensi akan mengalami kerusakan jantung), ginjal, otak, mata, serta organ tubuh lain (Susilo dan Wulandari, 2011:3). Suatu peningkatan dari tekanan darah sistole dan diastole meningkatkan resiko menimbulkan penyakit jantung (cardiac), penyakit ginjal (renal), pengerasan atau penggumpalan dari pembuluh darah (atherosclerosis), kerusakan mata, dan stroke (kerusakan otak).

Berdasarkan analisi univariat pada tabel 3 diketahui bahwa didapatkan p-value sebesar 0,000 sedangkan $\alpha$ sebesar 0,05 . Hal ini menyatakan bahwa $\alpha$ lebih besar dari p-value. Ini berarti Ha diterima Ho ditolak. Maka dapat disimpulkan bahwa ada penurunan tekanan darah yang signifikan sebelum dan sesudah diberikan rebusan seledri. Dengan kata lain, Hasil uji statistik didapatkan nilai p-value 0,000 dan $\alpha$ adalah 0,05 sebagai derajat kepercayaan pada penelitian ini. Maka dapat disimpulkan bahwa adanya perbedaan yang signifikan antara sebelum dan sesudah minum rebusan seledri terhadap penurunan tekanan darah pada penderita hipertensi di wilayah kerja puskesmas cenggu. 
Hipertensi bukan penyakit yang langsung dapat disembuhkan dengan pengobatan. Apabila seseorang sudah terkena hipertensi maka seumur hidupnya ia harus hati-hati dan terus menerus menjaga tekanan darahnya. Karena walau tekanan darah sudah normal tidak mustahil akan kembali terkena hipertensi. Untuk menjaga tekanan darah tetap normal yaitu dengan menjalani pola hidup sehat seperti melakukan olahraga secara teratur, menghindari stress dan mengontrol emosi, tidak atau berhenti merokok, serta tidur cukup setiap hari antara 6-8 jam. Selain itu juga dengan melakukan pola makan sehat yaitu dengan mengurangi konsumsi garam, mengkonsumsi makanan yang mengandung magnesium dan kalium, tidak mengkonsumsi alkohol, makan sayuran dan buahbuahan yang mengandung serat, mengendalikan kadar kolestrol, mengendalikan kadar gula darah dan mengendalikan berat badan. Pengobatan komplementer-alternatif yang salah satunya adalah terapi herbal walau penggunaannya lama, tapi efek sampingnya relatif kecil jika digunakan secara tepat, sehingga menjadi pilihan masyarakat untuk mengatasi hipertensi. Beberapa herbal yang telah melalui penelitian dan terbukti menurunkan tekanan darah tinggi diantaranya adalah seledri, belimbing manis, mentimun, bunga rosella, kumis kucing, daun dewa, lidah buaya, tempuyung, sambilato dan brotowali (Soeryoko, 2010:91).

Seledri (apium graveolens L.) adalah tumbuhan serba guna. Hampir semua bagian tanaman ini (daun, tangkai, umbi dan biji) semua bisa dimanfaatkan. Kandungan kimia yang telahdiketahui sekitar 156 komponen. Golongan utamanya adalah monoterpen, alcohol alifatik, komponen karbonil, fenol, epoksida aromatok, dan turunan phthalide. Senyawa utama yang terdapat pada seledri adalah limonene (214 $\mathrm{mg}$ per $\mathrm{kg}$ ). Seluruh bagian tanaman seledri mengandung provitamin A, vitamin B, vitamin C, dan vitamin $\mathrm{K}$.

Terjadinya perbedaan tekanan darah sebelum dan sesudah diberikan rebusan seledri adalah dikarenakan kandungan seledri yang berperan penting menurunkan tekanan darah, antara lain magnesium, pthalides, apigenin kalium dan asparagin. Magnesium dan pthalides berperan melenturkan pembuluh darah. Apegenin berfungsi untuk mencegah penyempitan pembuluh darah dan tekanan darah tinggi. Kalium dan asparagin bersifat diuretik, yaitu memperbanyak air seni sehingga volume darah berkurang. Menurut peneliti, pemberian rebusan seledri harus sesuai dengan takaran minumnya agar memberikan efek kepada seseorang yang meminumnya dan juga dengan melakukan pola hidup sehat dan pola makan sehat. Komunikasi atau penjelasan tentang manfaat seledri haruslah jelas agar responden bersedia untuk diberikan terapi.

\section{KESIMPULAN}

Sebagian besar Frekuensi Tekanan darah responden sebelum diberikan air rebusan seledriyaitu Hipertensi. Sebagian besar Frekuensi Tekanan darah responden Sesudah diberikan air rebusan seledriyaitu dalam batas normal sebanyak 14 responden dan hipertensi sebanyak 2 responden. Ada Pengaruh Penggunaan Rebusan Seledri Terhadap Penurunan Tekanan Darah Pada Penderita Hipertensi Di Wilayah Kerja Puskesmas Cenggu. 


\section{DAFTAR PUSTAKA}

Arikunto, S. (2002). Manajemen penelitian. Jakarta : PT Rineka Cipta

Dalimarta, S. (2005). Tanaman Obat di alingkungan Sekitar. Jakarta: Penerbit Puspa Swara

Gunawan. (2001). Hipertensi Tekanan Darah Tinggi. Yogyakarta: Kanisius

Guyton \& Hall. (2008). Fisiologi Manusia dan Mekanisme Penyakit. Edisi 7. Jakarta: EGC

Halimah \& Ekwantini, Rosa Delima. 2014. Jus Seledri (Apium Graveolens) Menurunkan Tekanan Darah Tikus Rattus Strain Wistar dengan Hipertensi.

Marlia. (2009). Merawat dan Menyembuhkan Hipertensi. Bandung: Kreasi Wacana

Soeryoko, Hery (Ed). 2010. 20 Tanaman Obat Terpopuler Penurun Hipertensi. Yogyakarta: C.V Andi Offset. 130 halaman.

Susilo, Yekti \& Wulandari, Ari. 2011. Cara Jitu Mengatasi Hipertensi. Yogyakarta: C.V Andi Offset. 196 halaman. 